\title{
CARACTERÍSTICAS DAS CÉLULAS PARASITADAS PELO TRYPANOSOMA $C R U Z I$ NA PAREDE DA VEIA CENTRAL DAS SUPRA-RENAIS DE CHAGÁSICOS CRÔNICOS
}

\section{Hipolito de Oliveira Almeida, Elizabeth Martins, José Umberto Franciscon, Vicente de Paula Antunes Teixeira, Alfredo José Afonso Barbosa, Helenice Gobbi e Marlene Antonia dos Reis}

\begin{abstract}
Foram analisados os aspectos das células musculares parasitadas pelo Trypanosoma cruzi, na veia da supra-renal de chagásicos crônicos, através de exame ao microscópio óptico de lâminas coradas pela hematoxilina-eosina (HE), PAS, Feulgen e peroxidase-antiperoxidase (PAP) para antigenos do T. cruzi. Além das modificaçōes nucleares descritas anteriormente, os leiomiócitos parasitados exibem alteraçóes citoplasmáticas que podem ser vistas mesmo em células que albergam poucos parasitas. As formas amastigotas geralmente estäo envoltas por halo claro e o citoplasma restante adquire aspecto granuloso ou reticular, basófilo pelo $H E$, sendo sempre PAS e Feulgen negativos. Estes dados sugerem que o material basófilo no citoplasma deve ser RNA ribossômico. A periferia dos ninhos que mostram uma "membrana" com reação do $P A P$ para antigenos do $\mathrm{T}$. cruzi fortemente positiva, poderia ser devida a reação cruzada de material celular rechaçado para a periferia ou a difusão de antígenos do T. cruzi e sua adsorção à periferia celular. O material citoplasmático $P A P$ positivo poderia resultar de artefato, de reação imunocitoquimica cruzada, de antigenos tripanossomóticos difundidos ou de antigenos tripanossoma-simile resultantes de interações entre o leiomiócito e o parasita.
\end{abstract}

Palavras chaves: Trypanosoma cruzi. Doença de Chagas. Músculo liso. Suprarenal. Veia central da supra-renal.

Há alguns anos iniciamos estudos que nos permitiram concluir ser a veia central das supra-renais uma importante sede de parasitismo nos chagásicos crônicos $^{314}$. Neste local observam-se com freqüência, modificações nucleares nas células parasitadas 4 , semelhantes às descritas por Rubio e Howard ${ }^{13} \mathrm{em}$ casos humanos congênitos da tripanossomose e por Torres e Azevedo 15 no tatu ("armadillo") infectado pelo $T$. cruzi. Acreditamos que uma exploração mais minuciosa destas células poderá contribuir para o melhor conhecimento da fase intracelular do ciclo biológico do parasita no chagásico crônico. No presente trabalho tentamos analisar os aspectos morfológicos e algumas caracteristicas histoquímicas do citoplasma de leiomiócitos da veia supra-renálica, parasitados pelo $T$. cruzi.

\section{MATERIAL E MÉTODOS}

Foram estudadas 40 secçōes de células parasitadas pelo $T$. cruzi na veia da medula das suprarenais de 8 chagásicos crônicos, coradas pela hemato-

\footnotetext{
Disciplinas de Patologia Geral e de Parasitologia da Faculdade de Medicina do Triângulo Mineiro (Uberaba) è de Anatomia Patológica da Universidade Federal de Minas Gerais (Belo Horizonte).

Recebido para publicação em $3 / 1 / 1986$
}

xilina-eosina (HE), 20 secções de células semelhantes, coradas pelo Feulgen e outras 20 pela técnica imunocitoquimica da peroxidase-antiperoxidase (PAP), de acordo com a padronização seguida por Barbosa ${ }^{6}$ e Barbosa e cols ${ }^{7}$. Este material foi obtido através de seleção preliminar que obedecia à seguinte padronização: as supra-renais de chagásicos crônicos eram fixadas em solução de formaldeido a $4 \%$, a seguir recortadas em vários fragmentos que eram incluidos em parafina e submetidos à microtomia seriada, sendo os cortes numerados, corando-se inicialmente pela hematoxilina-eosina apenas os numeros impares ou apenas os numeros pares. Nestes, era feita a procura de ninhos cujos locais eram marcados para estudo posterior. Algumas lâminas não coradas pela hematoxilina-eosina, proximas daquelas que apresentavam ninhos, eram coradas pelo método de Feulgen para DNA e outras pela técnica do PAP ou PAS. A seleção dos chagásicos crônicos era feita baseando-se nos achados anatômicos, associados às reações de imunofluorescência e de fixação do complemento positivas para T. cruzi.

\section{RESULTADOS}

Em dois casos o número de células musculares lisas parasitadas pelo $T$. cruzi na veia da supra-renal era grande, sendo fácil o encontro de mais de 10 ninhos 
Almeida HO. Martins E, Franciscon JU. Teixeira VPA, Barbosa AJA. Gobbi H, Reis MA Caracteristicas das celulas parasitadas pelo Trypanosoma cruz $i$ na parede da veia central das supra-renais de chagásicos crònicos. Revista da Sociedade Brasileira de Medicina Tropical 19:227-231. Out-Dez. 1986.

por seç̧ão transversa da veia em cada lâmina; nos demais encontrava-se um a 4 ninhos por caso. Nos casos com parasitismo mais abundante pudemos identificar células cuja secção mostrava de um a três parasitas envoltos por halos claros, situados perifericamente no citoplasma (Fig. 1). Este, em sua maior extensào,

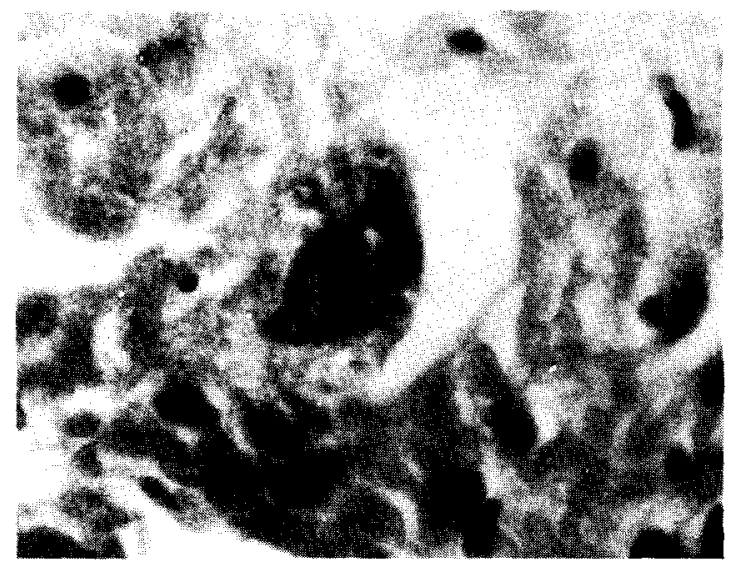

Fig. 1 - Musculatura da veia central da supra-renal de chagasico crónico - célula parasitada concendo pequeno numero de amastigotas, apresentando núcleo volumoso de contorno irregular e hipercromático;o citoplasma é abundante, finamente reticular, corando-se levemente pela hematoxilina (basofilo). Em tomo das amastigotas formou-se halos claros. Hematoxilina-eosina. x800.

perdia o aspecto fusitorme e a caracteristica miofibrilar acidófila, tornando-se oval por expansão do diâmetro transverso, assumindo uma característica de trama reticular ou de grânulos finos, com afinidade tintorial basofila, corando-se em um tom azul ou cinzaclaro em preparaçōes pela hematoxilina-eosina. $\mathrm{O}$ núcleo destas celulas apresenta-se aumentado, podendo exibir um ou dois nucleolos. Em outras células (Figs. 2 e 3 ) o número de parasitas é um pouco maior, estando eles isolados ou em pequenos grupos no interior de grandes espaços claros completa ou incompletamente delimitados por septos ou "membranas". Estas lojas opticamente vazias contendo formas amastigotas do $T$. cruzi, geralmente dispōem-se perifericamente no citoplasma, em cuja parte central freqüentemente observa-se material granuloso, basofilo, as vezes associado a pequena quantidade de material acidófilo. Quando presente, o núcleo è volumoso e mostra-se envolvido pelo citoplasma granuloso da célula hospedeira. $\mathrm{O}$ contorno do ninho é marcado por uma "membrana" interna basófila, de espessura um pouco irregular, externamente à qual, geralmente pode-se observar uma faixa eosinófila, homogênea, compactada de citoplasma muscular que circunda todo o ninho, sem que se possa dizer se é citoplasma de

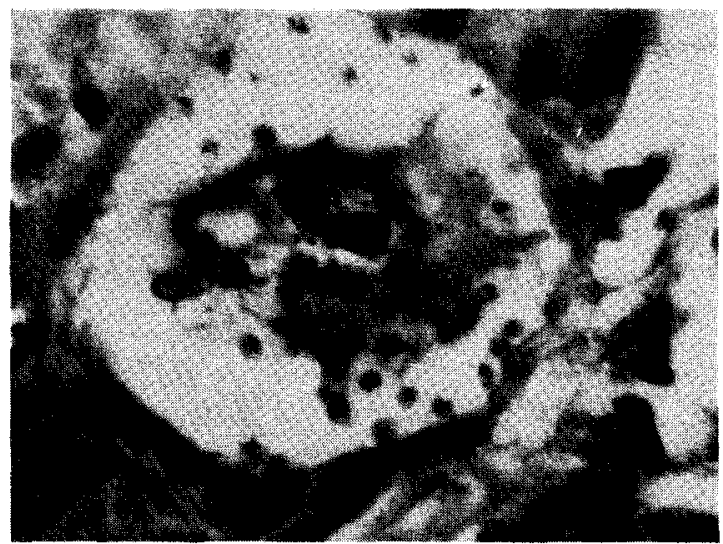

Fig. 2 - Celula da camada muscular da veia da suprarenal de chagásico crónico apresentando núcleo volumoso, claro e de contorno mal definido. Junto a um dos pólos do nucleo o citoplasma apresenta-se formado predominantemente por finos grânulos basófilos; o resto do citoplasma é formado por amplo espaço claro contendo algumas amastigoras. Hematoxilina-eosina. $x 1250$.

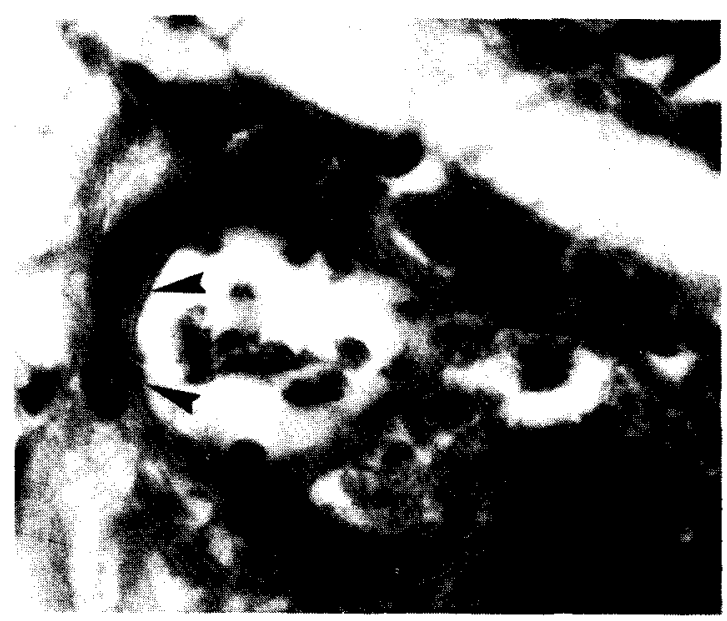

Fig. 3 - Musculatura da parede da veia da supra-renal $\mathrm{Na}$ intimidade de um fasciculo muscular observam-se dois ninhos de amastigoras: o da direita apresenta alguns parasitas e material citoplasmatico granuloso; o da esquerda mostra um citoplasma claro contendo algumas amastigotas e na sua periferia vè-se estrutura membranosa formando a parede interna do ninho (setas). Hematoxilina-eosina. $x 800$

células musculares adjacentes ou da própria miocelula parasitada. Às vezes a celula parasitada apresenta apenas pequena porçào de citoplasma granuloso junto ao núcleo volumoso e grande espaço citoplasmático sem afinidade tintorial, contendo algumas formas amastigotas, formando um nitido contraste entre o 
Almeida HO, Martins E. Franciscon JU, Teixeira VPA, Barbosa AJA. Gobbi H, Reis MA. Caracteristicas das celulas parasitadas pelo Trypanosoma cruzi na parede da veia central das supra-renais de chagásicos crónicos. Revista da Sociedade Brasileira de Medicina Tropical 19: 227-231. Out-Dez, 1986

grande espaço citoplasmático e o pequeno número de parasitas que o ocupa. Outros ninhos apresentam-se volumosos e com grande número de parasitas que preenche praticamente todo o seu espaço citoplasmático. Nestas células com muitos parasitas o núcleo é mais difícil de ser visto e, quando presente, pode apresentar grau variável de encarquilhamento e/ou cromatina com tendência à homogeinização e hipercromatismo e, às vezes, desaparecimento da membrana cromatínica. Quando as células parasitadas são coradas pelo método Feulgen para DNA (Fig. 5), em seus núcleos evidencia-se a imagem negativa dos nucléolos e no citoplasma o material granuloso é negativo, sendo o núcleo e o cinetoplasto das amastigotas intensamente corados, tornando a identificação dos parasitas muito fácil por este método. A reação do PAS (àcido periodico de Schiff) não cora nem a membrana basófila da periferia do ninho, nem o material basófilo granuloso do seu citoplasma e nem o corpo do parasita. Já a técnica da peroxidase antiperoxidase para $T$. cruzi (Fig. 4), alem de corar bem as amastigotas,

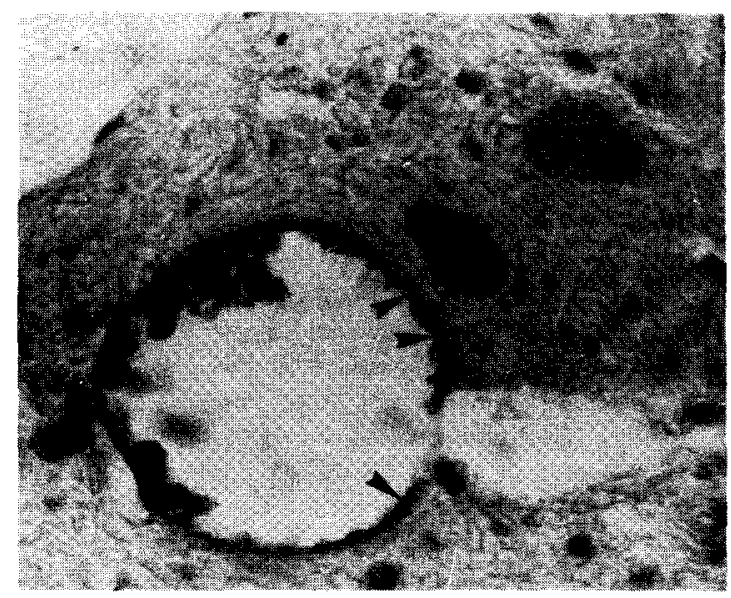

Fig. 4 - Ninhos de amastigotas na veia central da suprarenal de chagásico crônico, corado pelo método da peroxidase antiperoxidase (PAP) para $\mathrm{T}$. cruzi Proximo ao canto superior direito célula parasitada contendo apenas uma amastigota com reacào fortemente positiva enquanto o citoplasma contém gránulos que se coram fracamente pelo PAP. Embaixo à esquerda observa-se volumoso ninho cuja "membrana" periférica (setas) é fortemente positiva pelo PAP, como as amastigotas. Entre os dois ninhos descritos observa-se um terceiro cujo conteudo cora-se intensamente pelo PAP. x640.

mostra-se fortemente positiva ao nivel da membrana periferica (basófila pelo $\mathrm{HE}$ ) do ninho e ao nivel de alguns septos que dividem os espaços opticamente vazios que contêm parasitas. O material citoplasmático granuloso e basófilo que é Feulgen e PAS negativos pode mostrar-se fraca ou moderadamente positivo pelo PAP em algumas células parasitadas.

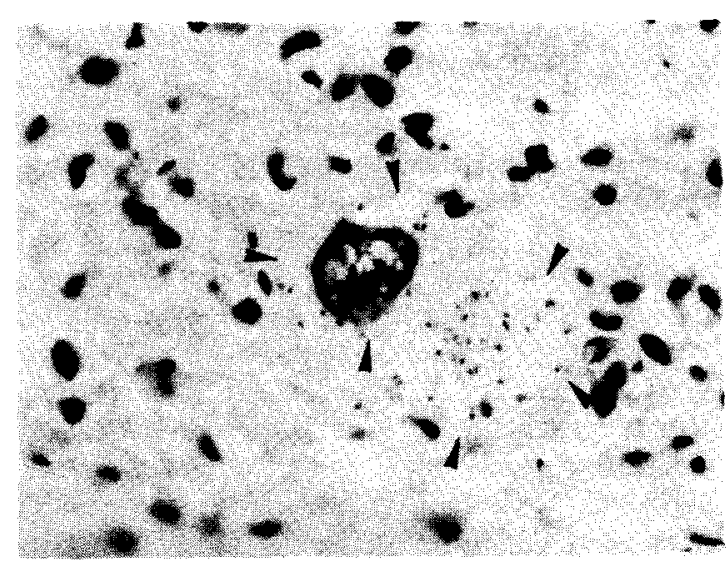

Fig. 5 - Dois ninhos de amastigotas do T. cruzi (setas) na musculatura da veia central da supra-renal de chagásico crónico, corados pelo método de Feulgen para DNA. O cinetoplasto e o núcleo dos amastigotas coram-se fortemente da mesma forma que o núcleo de uma das celulas hospedeiras. Material citoplasmatico de ambas as celulas hospedeiras Feulgen negativo. $\times 500$.

\section{DISCUSSÃO}

Estudos da interaçào entre o $T$. cruzi e células de vertebrados foram desenvolvidos "in vitro" por Dvorak e $\operatorname{col}^{9}$, Nogueira e col ${ }^{12}$, Luban e cols ${ }^{10}$, Meirelles e cols ${ }^{11}$ e Alexander ${ }^{1}$ dentre outros. Extensa revisão e discussão sobre os vảrios aspectos da relação hospedeiro-parasita na tripanossomose cruzi e feita por Brener ${ }^{8}$. Apesar da existência de expressiva soma de trabalhos publicados abordando diferentes ângulos desta protozoose, pouca atenção tem sido dada às células musculares lisas parasftadas pelo $T$. cruzi, na fase crônica da doença humana e mesmo experimental. Em trabalhos anteriores 45 chamamos a atenção para as modificações nucleares que se observam freqüentemente em cèlulas musculares lisas da veia da supra-renal de chagásicos crónicos parasitadas pelo $T$. cruzi. Recentemente observamos gigantismo nuclear em célula muscular cardiaca de chagásico crónico com formas amastigotas do $T$. cruzi ${ }^{2}$. O presente trabalho trás novas contribuiçōes, mostrando as modificaçōes citoplasmáticas que ocorrem nas cèlulas musculares lisas parasitadas em supra-renais de chagásicos crônicos. Pode-se dizer que o parasitismo dos leiomiocitos além de promover as modificações nucleares citadas, induz alterações citoplasmaticas que podem ser vistas mesmo em secçoes de células que albergam apenas um ou poucos parasitas. Geralmente a forma amastigota do $T$. cruzi, mesmo quando única na secção celular, mostra-se envolta por halo claro (opticamente vazio), nitidamente separado do resto do citoplasma. $O$ citoplasma restante perde a caracteris- 
Almeida HO, Martins E, Franciscon JU, Teixeira VPA, Barbosa AJA, Gobbi H, Reis MA. Caracteristicas das células parasitadas pelo Trypanosoma cruzi na parede da veia central das supra-renais de chagásicos crônicos. Revista da Sociedade Brasileira de Medicina Tropical 19: 227-231, Out-Dez, 1986.

tica miofibrilar acidófila e adquire aspecto finamente reticular ou granuloso, corando-se moderadamente pela hematoxilina (basófilo), sendo Feulgen e PAS negativos. Estes dados histoquímicos levam-nos a admitir que a basofilia do citoplasma da célula parasitada seja devida a aumento do teor de RNA, particularmente o ribossômico, o que está de acordo com as características assumidas pelos núcleos que além de volumosos apresentam, às vezes, excepcional desenvolvimento nucleolar ${ }^{5}$. À medida que as formas amastigotas aumentam em número os halos claros são transformados em "lojas" periféricas, delimitadas por septos, às vezes com membrana interna basófila que pode existir também contornando todo o ninho. Estas "lojas" têm grandes espaços opticamente vazios, que são apenas parcialmente preenchidos por grupos de amastigotas pouco numerosos, mas que podem ser volumosos. $O$ citoplasma sem parasitas, geralmente se concentra em torno do núcleo e contém material finamente granuloso e basófilo, podendo ainda apresentarse constituido por grânulos um pouco mais grosseiros, em parte basófilos e em parte ligeiramente acidófilos. Enquanto as amastigotas mostram núcleo e cinetoplasto facilmente identificáveis pelo Feulgen, o citoplasma da célula hospedeira mantém-se Feulgen e PAS negativos. Entretanto, em algumas células semelhantes às descritas acima, a técnica da peroxidase antiperoxidase para $T$. cruzi, além de demonstrar suas formas amastigotas, coram substâncias livres no citoplasma granuloso da célula hospedeira e, às vezes, esta reação é fortemente positiva na "membrana" que envolve todo o ninho, podendo sê-lo também nas membranas que delimitam as lojas. Estas membranas poderiam ser explicadas tanto por reação imunocitoquímica cruzada de material celular rechaçado para a periferia da célula hospedeira como também por difusão de antigenos do $T$. cruzi e adsorção dos mesmos às estruturas da periferia celular. Já o material citoplasmático granuloso, cuja positividade pelo PAP é menos acentuada, poderia resultar de reação imunocitoquímica cruzada ou simplesmente de um artefato (background), podendo também constituir-se de antigenos tripanossoma-simile resultantes de interação entre o leiomiócito e o parasita.

\section{$S U M M A R Y$}

Some morphologic aspects of the smooth muscle cells, parasitised by $\mathrm{T}$. cruzi in the adrenal vein of chronic chagasic patients were studied. The staining techniques used were the following: Hematoxylin and Eosin (HE), PAS, Feulgen and the peroxidase antiperoxidase (PAP) immunocytochemical method for identification of $\mathrm{T}$. cruzi antigen. The intracellular amastigotes were often surrounded by a clear halo and the cytoplasm of the parasitised smooth muscle cells were granular or reticular in appearance being basophil and, PAS and Feulgen negative. These data suggest that the cytoplasmatic basophil material could be ribosomic RNA. The intracellular nests of amastigotes were surrounded by a PAP positive "membrane-like" structures. This PAP positive "membrane-like" material, as well as some cytoplasmatic PAP positive granulomatous material, could be due to absorbed antigens from the parasite or to $\mathrm{T}$. cruzilike antigens resulted from the interaction between the parasite and the host cell.

Key words: Trypanosoma cruzi. Chagas' disease. Smooth muscle of the central suprarenal vein.

\section{REFERÊNCIAS BIBLIOGRÁFICAS}

1. Alexander J. Effect of the antiphagocytic agent cytochalasin B on macrophage invasion by leishmania mexicana promastigotes and Trypanosoma cruzi epimastigotes. Journal of Protozoology 22: 237-240, 1975.

2. Almeida HO. Gigantismo nuclear em célula muscular cardiaca parasitada pelo Trypanosoma cruzi. Revista da Sociedade Brasileira de Medicina Tropical 18: 121-122, 1985.

3. Almeida HO, Teixeira VPA, Oliveira ACF. Flebite com parasitismo em supra-renais de chagásicos crônicos. Arquivos Brasileiros de Cardiologia 36: 341-344, 1981.

4. Almeida HO, Teixeira VPA, Oliveira ACF. Alteraçōes nucleares em células parasitadas pelo $T$. cruzi. Revista de Patologia Tropical 10: 15-20, 1981.

5. Almeida HO, Teixeira VPA, Reis MA, Franciscon JU, Martins E. Modificaçōes nucleares em células de chagásicos crônicos parasitadas pelo $T$. cruzi. Revista da Sociedade Brasileira de Medicina Tropical, em preparaçāo.

6. Barbosa AJA. Metodo imunocitoquimico para identificação de amastigotas do Trypanosoma cruzi em cortes histológicos de rotina. Revista do Instituto de Medicina Tropical de São Paulo 27: 293-297, 1985.

7. Barbosa AJA, Gobbi H, Lino BT, Lages-Silva E, Ramirez E, Teixeira VPA, Almeida HO. Estudo comparativo entre o método convencional e o método da peroxidase antiperoxidase na pesquisa do parasitismo tissular na cardiopatia chagásica crônica. Revista do Instituto de Medicina Tropical de Sāo Paulo 28: 91-96, 1986.

8. Brener Z. O parasito: relações hospedeiro-parasito. In: Brener Z. e Andrade Z. Trupanosoma cruzi e Doença de Chagas. Editora Guanabara-Koogan, Rio de Janeiro, p. 1-41, 1979.

9. Diorak J. Schmunis C. Trypanosoma cruzi: interaction with mouse peritonial macrophages. Experimental $\mathrm{Pa}$ rasitology 32: 289-300, 1972.

10. Luban N, Dvorak J. Trypanosoma cruzi: interactions with vertebrate cells "in vitro". III. Selection for biological characteristics following intracellular passage. Experimental Parasitology 36: 139-143, 1974.

11. Meirelles MNL, Martinez-Palomo A, Souto-Padron J, De Souza W. Participation of concanavalin A binding 
Almeida HO, Martins E, Franciscon JU, Teixeira VPA, Barbosa AJA, Gobbi HI, Reis MA. Caracteristicas das células parasitadas pelo Trypanosoma cruzi na parede da veia central das supra-renais de chagásicos crônicos. Revista da Sociedade Brasileira de Medicina Tropical 19: 227-231, Out-Dez, 1986.

sites in the interaction between Trypanosoma cruzi and macrophages. Journal Cell Science: 62: 287-299, 1983.

12. Nogueira N, Cohn Z. Trypanosoma cruzi: mechanism of entry and intracellular fate in mammalian cells. Journal of Experimental Medicine 143: 1402-1420, 1976.

13. Rubio $M$. Howard J. Observación de células gigantes parasitadas por Trypanosoma cruzi en niños con enfermedad de Chagas congénita. Biológica 34:50-60, 1963.
14. Teixeira VPA. Parasitismo da veia central da suprarenal em diferentes formas anátomo-clinicas da doença de Chagas. Tese de Mestrado. Universidade Federal de Minas Gerais, 86p., 1985.

15. Torres CM, Azevedo AP. Cellules geantes kistiques chez le chien l'armadillo que presente l'infection spontanee par le Trypanosoma cruzi: Chagas, 1909. Comptes Redus de la Société Biologie 102: 412-414, 1929. 